\title{
MODELO(S) DE JUSTIÇA CONSTITUCIONAL NA AMÉRICA DO SUL
}

http://dx.doi.org/10.21527/2176-6622.2020.53.106-115

Recebido em: 16/10/2019

Modificações solicitadas em: 18/11/2019

Aceito em: 20/1/2020

Danielle Sales Echaiz Espinoza

Doutora em Direito pelo Programa de Pós-Graduação da Pontifícia Universidade Católica do Rio Grande do Sul (2019). Mestre em Direito Público pela Universidade Federal de Alagoas (2008). Especialista em Direito Constitucional pelo Centro de Estudos Superiores de Maceió (2006) e graduada em Direito pela Universidade Federal do Ceará (2000). Professora de Direito Constitucional do Centro Universitário Cesmac. http:// lattes.cnpq.br/3464455893088027. https://orcid.org/0000-0002-5366-8093. daniellechaiz@uol.com.br

\section{RESUMO}

O presente artigo analisa os sistemas de justiça constitucional de cinco países da América do Sul - Chile, Peru, Paraguai, Venezuela e Argentina - com o objetivo de demonstrar as dificuldades para a elaboração de um ou vários modelos de justiça constitucional para a região. Aborda a proposta clássica de Louis Favoreu acerca dos modelos de justiça constitucional e também enfrenta a tese de Pablo Pérez Tremps sobre a adoção de uma tipologia de sistemas de justiça constitucional na América Latina, contrastando-as com a organização da justiça constitucional em cada um desses países. As peculiaridades encontradas nesse grupo sugerem que é impossível se estabelecer um modelo único de justiça constitucional sul-americana e que qualquer tentativa de se elaborar sistemas para enquadrar os países da região deverá enfrentar uma enorme dificuldade para agrupar organizações tão diversificadas.

Palavras-chave: Direito constitucional comparado. Justiça constitucional. Modelos de controle de constitucionalidade.

\section{CONSTITUTIONAL JUSTICE MODEL (S) IN SOUTH AMERICA}

\section{ABSTRACT}

The present study analyzes the constitutional justice systems of five South American countries - Chile, Peru, Paraguay, Venezuela and Argentina, with the objective of demonstrating the difficulties for the development of one or more models of constitutional justice to the region. Addresses the classic proposal of Louis Favoreu on the models of constitutional justice and also faces Pablo Pérez Tremps's thesis on the adoption of a typology of constitutional justice systems in Latin America, by contrasting them with the organization of constitutional justice in each of these countries. The peculiarities found in this group suggest that it is impossible to establish a unique model of constitutional justice South - American and that any attempt to develop systems to frame the countries of the region must face enormous difficulty in grouping such diversified organizations.

Keywords: Comparative constitutional law. Constitutional justice. Constitutionality control models.

\section{SUMÁRIO}

1 Introdução. 2 Sistemas de justiça constitucional na América Latina - proposta de Pablo Pérez Tremps. 3 Justiça constitucional no Chile. 4 Justiça constitucional no Peru. 5 Justiça constitucional no Paraguai. 6 Justiça constitucional na Venezuela. 7 Justiça constitucional na Argentina. 8 Convergência de modelos, hibridização e mudanças na caracterização de um sistema de jurisdição constitucional. 9 Conclusão. 10 Referências. 


\section{INTRODUÇÃO}

Em seu magistral estudo sobre as Cortes Constitucionais, Favoreu (2004) analisa a organização da justiça constitucional em diversos países sob a perspectiva do modelo europeu de justiça constitucional concentrada.

São características comuns desse modelo: o contexto institucional e jurídico particular com dualidade de jurisdições (contencioso administrativo e contencioso ordinário), a especialização do contencioso constitucional em órgão autônomo, fora da instância judicial, responsável pelo monopólio no exercício da justiça constitucional, a indicação política dos membros desses tribunais - que nem sempre serão juízes de carreira - e a concentração da competência para realizar o controle de constitucionalidade com eficácia erga omnes, seja por via principal (por ação direta) seja por via incidental (por meio de recurso da parte ou por via de remessas de autos).

Contrapondo-se a este, situa-se o modelo estadunidense de justiça constitucional difusa, cujas características gerais poderiam ser reunidas nos seguintes traços: exercício da jurisdição constitucional pela justiça ordinária, a possível presença da questão constitucional em qualquer litígio, a ausência de contencioso constitucional - o que se deve em parte à unidade da jurisdição norte-americana, na qual não existe diferença entre tribunais administrativos e tribunais judiciários - e a eficácia inter partes das decisões.

A experiência fracassada de alguns países europeus com o controle difuso (na Alemanha de Weimar) e a desconfiança generalizada no Poder Judiciário ante a postura complacente de juízes ordinários durante os regimes nazi-fascistas, foram fatores que também contribuíram para a rejeição do modelo estadunidense e que justificaram a opção feita por boa parte dos países da Europa continental do pós-guerra pelo modelo de justiça constitucional kelseniana (austríaca).

Uma das dificuldades com que o autor se depara, que é particularmente relevante para o presente estudo, refere-se à caracterização da justiça constitucional dos países latino-americanos. Não houve, de fato, nas outras Américas (Central e do Sul), a escolha por um dos modelos assinalados, mas a integração dos dois, o que levou Favoreu (2004, p. 135) a considerar que "[...] ao lado dos modelos estadunidense e europeu, há também um modelo sul-americano, cujas características comuns ainda não foram definidas".

Haveria realmente a possibilidade de se definir um modelo de justiça constitucional sul-americano? Diante da aguda hibridização dos modelos clássicos nesses países não seria melhor se falar em diversos modelos? Ou, ainda, em razão da diversidade de combinações em que se insere a justiça constitucional sul-americana, não seria mais apropriado falar em critérios de classificação do que em modelos abrangentes de jurisdição constitucional?

São questões sobre as quais o trabalho pretende se debruçar, mediante a análise comparada da organização da justiça constitucional em alguns países da América do Sul. A seleção dos países teve por base a proposta de Pablo Perez Tremps (2003) acerca dos diversos sistemas de justiça constitucional na América Latina.

\section{SISTEMAS DE JUSTIÇA CONSTITUCIONAL NA AMÉRICA LATINA - PROPOSTA DE PABLO PÉREZ TREMPS}

Segundo Belaunde (2004), os países recém-independentes da América Latina foram profundamente influenciados por dois sistemas jurídicos: o francês e o norte-americano. A influência francesa foi evidente na estruturação do poder político, sobretudo na limitação do Estado diante dos direitos do homem e da doutrina da separação dos Poderes.

Já dos Estados Unidos, considerados exemplos mais próximos de colônias independentes de sucesso, foram herdados o sistema de governo presidencialista e o Estado Federal. Como também ressalta o autor, a ampla divulgação de duas literaturas jurídicas específicas ("The federalist papers" e "La demócratie em Amé-

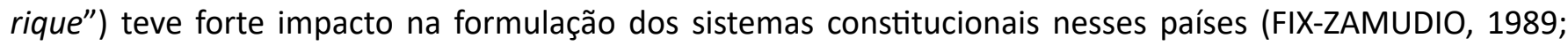
BALAUNDE, 2004).

Em razão disso, praticamente todos os países da América Latina, até meados do século 20, haviam incorporado o modelo norte-americano de controle de constitucionalidade em seus ordenamentos. $\mathrm{O}$ transplante legal da revisão judicial norte-americana para o contexto hispânico e português, tradicionalmente associado 


\section{Debate}

ao sistema romano-germânico, como adverte Fix-Zamudio (1989), provocou o surgimento de institutos processuais bem peculiares que se distanciam do modelo original, como a criação do recurso de inconstitucionalidade perante a Corte, com competência específica para apreciá-lo.

A influência do modelo europeu apenas se fez sentir a partir da década de 30 do século 20. Ainda assim, é preciso ressaltar que, antes mesmo da execução do modelo de justiça concentrada kelseniano na Áustria em 1920, já havia surgido, em alguns países sul-americanos, como a Colômbia (1910) e a Venezuela (1893), mecanismos de jurisdição concentrada, inclusive com a criação da ação popular de inconstitucionalidade com efeitos erga omnes (BALAUNDE, 2004).

Nesse sentido, diversos elementos do modelo europeu foram sendo introduzidos nos ordenamentos jurídicos da região: na Bolívia, a Constituição de 1967 atribuiu à Corte Suprema o monopólio no exercício do controle incidental de constitucionalidade, com efeitos inter partes (ALCALÁ, 2003); no Brasil, a Constituição de 1934 criou um mecanismo para conferir eficácia geral às decisões do Supremo Tribunal Federal em sede de controle de constitucionalidade difuso, e a Constituição de 1946 introduziu a ação direta de inconstitucionalidade interventiva; no Chile, a Constituição de 1925 designava o controle de constitucionalidade incidental à Corte Suprema de Justiça; o Equador, em 1945, e o Peru, em 1979, criaram o Tribunal de Garantias Constitucionais (ALCALÁ, 2003).

A influência dos tribunais constitucionais europeus no segundo pós-guerra, o restabelecimento dos regimes democráticos na América Latina, bem como a intensa circulação de literatura jurídica neoconstitucionalista, proporcionaram, a partir da década de 80 do século 20, um fortalecimento da jurisdição constitucional na região. Muitos países, inclusive (como Chile, Colômbia, Bolívia, Peru e Equador), criaram seus próprios tribunais constitucionais (VILLALOBOS, 2010).

Nesse cenário, fica muito difícil manter a dicotomia modelo estadunidense versus modelo europeu para analisar a disposição da justiça constitucional na América Latina.

Como destaca Segado (2014), a América Latina é um verdadeiro "laboratório" de jusrisdição constitucional, criando institutos processuais diversos e evidenciando uma contundente hibridização dos modelos tradicionais. Se, porém, os sistemas de justiça constitucional na região não se encaixam em nenhum deles, seria possível reconduzi-los a um modelo próprio ou sul-americano, como imaginou Favoreu (2004)?

Parece uma hipótese bem difícil de construir, mesmo que se intente defender um modelo misto de justiça constitucional, pois as contingências de cada país irão demonstrar que não há uniformidade nos elementos adotados de um ou outro modelo clássico.

Além disso, se por jurisdição constitucional deva se entender não apenas o controle de constitucionalidade de normas (proteção da ordem objetiva constitucional ou jurisdição constitucional orgânica), mas também a defesa dos direitos fundamentais (proteção da ordem constitucional subjetiva, por meio das garantias constitucionais - como habeas data, habeas corpus, mandado de segurança, denominada de jurisdição constitucional das liberdades), a caracterização do sistema de justiça constitucional ficará bem mais complexa.

$\mathrm{Na}$ tentativa de elaborar critérios para a identificação de modelos de justiça constitucional na América Latina, Tremps (2003) identifica, ao menos, três sistemas:

1. Sistema de Tribunal Constitucional - tribunal situado fora do Poder Judiciário, autônomo, especializado e especial que exerce com monopólio ou não a jurisdição constituicional (Bolívia, Colômbia, Chile, Peru, Equador, Guatemala).

2. Sistema de órgão especializado dentro do Poder Judiciário (Costa Rica, Paraguai, Venezuela).

3. Sistema de atribuição de justiça constitucional a órgãos judiciais não especializados (Argentina, Brasil, México).

Como observa o autor, a existência de tribunais especializados não significa que outros tribunais ou instâncias não possam realizar compartilhadamente o controle de constitucionalidade, o que torna possível identificar não apenas um sistema no item 1) disposto supra, mas, de fato dois: a) sistema de tribunal constitucional com monopólio da jusrisdição constitucional e b) sistema de tribunal constitucional com exercício da jurisdição compartilhada com outros órgãos.

Partindo da proposta de Tremps, seriam identificáveis, assim, quatro sistemas de justiça constitucional na região: 
1. Sistema de tribunal constitucional com monopólio da jusrisdição constitucional.

2. Sistema de tribunal constitucional com exercício da jurisdição compartilhada com outros órgãos.

3. Sistema de órgão judicial especializado.

4. Sistema de atribuição de justiça constitucional a órgãos judiciais não especializados.

Embora tal proposta já contemple em si uma ampla diversidade de sistemas, seria realmente adequada para abranger as peculiaridades da justiça constitucional apenas na América do Sul? Selecionamos cinco países da região que podem ilustrar a insuficiência ou inadequação da proposta de Tremps: Chile, Peru, Paraguai, Venezuela e Argentina.

\section{JUSTIÇA CONSTITUCIONAL NO CHILE}

A Constituição chilena de 1925 atribuiu à Corte Suprema a possibilidade de declarar inaplicável um preceito legal contrário às disposições constitucionais, seja por iniciativa própria nos processos de sua alçada ou pela via de recursos das partes.

Os tribunais de primeira instância e as cortes de apelação não poderiam declarar a inaplicação da lei inconstitucional, tampouco poderiam suscitar a questão por meio de recurso à Corte Suprema. Como registra Alcalá (2003), havia uma forte concepção instalada na Constituinte de 1925 de que atribuir o controle de constitucionalidade das leis aos tribunais ordinários acabaria politizando os juízes e, por isso, tal técnica deveria ser evitada.

Essa ideia permaneceu arraigada na prática judicial chilena, revelando-se, mais tarde, responsável pelo conservadorismo e timidez da Corte Constitucional instaurada em 1980. Segundo considerações de Couso e Hilbink (2010), durante muito tempo, e por raízes históricas de interferência do Executivo no Poder Judiciário, tanto a corte constitucional quanto juízes ordinários se eximiram de realizar uma defesa firme dos direitos fundamentais e da ordem constitucional, demonstrando uma completa indiferença política.

Este cenário somente começou a ser modificado, segundo os autores supracitados, em 2006, quando a Corte abandona suas posições formalistas e exegéticas para adotar uma postura mais influente e firme na defesa da Constituição.

A Constituição vigente de 1980 criou o Tribunal Constitucional como órgão independente, fora do poder judicial, com competência para exercer a jurisdição constitucional de forma especializada. Originalmente, era encarregado de exercer o controle preventivo das leis, com eficácia erga omnes. Tratava-se de jurisdição concentrada, mas dividida com a Corte Suprema que exercia o controle posterior das leis, mediante o instituto do recurso de inaplicabilidade com efeitos inter partes (ALVARÉZ, 2007).

A reforma constitucional, instituída em 2005, reformulou a jurisdição constitucional chilena, alterou o número de membros do Tribunal Constitucional, de sete para dez, e modificou a nomeação dos mesmos, eliminando a participação do Conselho de Segurança Nacional que, antes, designava dois membros - passando a ser integrado por três membros indicados pelo presidente, três pela Corte Suprema e quatro pelo Senado e pela Câmara (ALVARÉZ, 2007).

Uma das maiores alterações foi a supressão do controle de constitucionalidade realizado pela Corte Suprema. A partir de então, o Tribunal Constitucional passou a exercer, com exclusividade, o controle de constitucionalidade de normas, tanto preventivo quanto repressivo, recebendo, inclusive, o recurso de inconstitucionalidade que, além de continuar à disposição da parte litigante, passou a estar disponível também aos juízes e tribunais ordinários. Nas palavras de Alvaréz (2007, p. 257), a reforma acabou

[...] con esta dualidade perturbadora de organos y sistemas. Concluye en Chile el controle concentrado, pero compartido, entre los tribunales de naturaleza diferente; y concluye la dispersión entre el control preventivo y el control correctivo o remedial de preceptos legales. Pero, principalmente, se pone fin a dos interpretaciones contrapuestas de la Constitución que llegaran a generar incerteza e inseguridad jurídica.

Dessa forma, a organização atual da justiça constitucional chilena evidencia um sistema de tribunal constitucional com monopólio no exercício do controle de constitucionalidade tanto pela via abstrata/principal quanto pela via concreta/incidental. 


\section{Debate}

Não se pode afirmar, contudo, que seria um sistema de tribunal constitucional com monopólio de jurisdição constitucional, tendo em vista que a defesa de liberdades, ou seja, a tutela dos direitos fundamentais (ou jurisdição constitucional subjetiva) continua, no sistema chileno, a ser realizada pelas Cortes de apelação e pela Corte Suprema nos casos de sua competência, seja por meio do recurso de proteção - semelhante à ação de amparo espanhol ou mandado de segurança brasileiro - seja em sede de habeas corpus (COUSO; HILBINK, 2010). Tal constatação impossibilita o enquadramento da justiça constitucional chilena no sistema de Tribunal Constitucional com monopólio de jurisdição constitucional.

\section{JUSTIÇA CONSTITUCIONAL NO PERU}

A Constituição peruana de 1826, profundamente influenciada pela Constituição napoleônica, estabeleceu o controle político de constitucionalidade a ser realizado pelo Senado. Essa tradição foi seguida por constituições posteriores (pela de 1826, de 1828, de 1834 e de 1839), com uma pequena alteração no órgão de controle que passa a ser o Congresso. Apenas na Constituição de 1856 surge o princípio da nulidade da lei contrária à Constituição (SUÁREZ, 2014).

Como assinala Suárez (2014), contudo, é possível identificar alguns precedentes, desde 1920, da Corte Suprema, nos quais afirma seu poder para realizar o controle difuso. O mais famoso foi o caso do jornalista Luis Pardo, preso em 1920 por oposição ao regime político autoritário da época. Após a notícia de que tinha interposto um habeas corpus, as autoridades o expulsaram do país. Pardo recorreu à Corte Suprema para anular seu ato de expulsão, alegando ofensa às garantias constitucionais, e a Corte decidiu a seu favor.

A lei orgânica do Poder Judiciário, aprovada em 1936, regulamentou, em previsão expressa, o controle difuso a ser realizado por qualquer juiz ou tribunal, tendo a Corte Suprema de se manifestar em última instância sobre a questão. De acordo com a análise de Suárez (2014), em razão do forte positivismo jurídico predominante na época, durante muito tempo o instituto ficou praticamente sem aplicação.

Com a Constituição de 1979, introduziu-se (ao lado do controle difuso) o controle concentrado de constitucionalidade no país. Era exercido pelo Tribunal de Garantias Constitucionais que detinha a competência para julgar as ações diretas e abstratas de inconstitucionalidade, com efeitos erga omnes e rever decisões denegatórias de habeas corpus e amparo das cortes de apelação.

O tribunal integrava o Poder Judiciário e, conforme relato de Alcalá (2003), sua atuação foi ineficaz na proteção de direitos, o que se devia, em parte, ao contexto político, social e econômico instável marcado por terrorismo e profunda crise econômica.

A Constituição vigente desde 1993, manteve o controle concentrado ao lado do controle difuso de forma bastante peculiar, estabelecendo o que Saraiva (2014) denomina de "circuito de jurisdição constitucional".

Tal circuito coordena o Tribunal Constitucional - órgão autônomo, fora da estrutura judicial - com o Poder Judiciário, cabendo ao primeiro precipuamente o julgamento da ação direta de inconstitucionalidade com efeitos erga omnes e, ao segundo, o controle difuso. Nesse último caso, os juízes e tribunais exercem o controle incidental no caso concreto, e o órgão que definirá em última instância a matéria não será o Tribunal Constitucional, mas a Corte Suprema, por meio de sua Câmara Constitucional (SARAIVA, 2014).

Vale frisar que na hipótese do controle difuso, ainda que realizado pela Câmara Constitucional da Corte Suprema, as decisões terão sempre efeito inter partes e os juízes e tribunais se limitarão a declarar a inaplicabilidade da norma por incompatibilidade com a Constituição. A atuação da Câmara Constitucional, ao revisar as questões vindas de outras instâncias, funciona como um mecanismo de uniformização de jurisprudência (SARAIVA, 2014).

O interessante é que há disposição expressa em lei que, no exercício do controle difuso, os juízes e órgãos judiciais, inclusive a Câmara Constitucional, devem interpretar as normas conforme os princípios e preceitos estabelecidos pelo Tribunal Constitucional, intérprete supremo da Constituição (SARAIVA, 2014).

A partir dessas considerações fica difícil enquadrar o Peru simplesmente no primeiro sistema de justiça constitucional de Tremps - sistema de tribunal constitucional com monopólio da jurisdição constitucional. É verdade que há Tribunal Constitucional, mas este não exerce o monopólio de jurisdição constitucional, uma vez que claramente o controle difuso é exercido pelas instâncias judiciais. 
Por outro lado, há um órgão judicial especializado (segundo sistema proposto por Tremps - sistema de tribunal constitucional com exercício da jurisdição compartilhada com outros órgãos) e a Câmara Constitucional, que funciona como última instância do controle difuso e realiza a uniformização da matéria constitucional ainda não apreciada pelo Tribunal Constitucional.

Dessa forma, os critérios de Tremps - como existência de um Tribunal Constitucional e a presença de um órgão judicial especializado - deveriam mesclar-se para refletir adequadamente a realidade da Jurisdição constitucional peruana.

\section{JUSTIÇA CONSTITUCIONAL NO PARAGUAI}

A lei orgânica dos Tribunais de 1918 introduziu no ordenamento jurídico paraguaio a possiblidade de a mais alta Corte do país na época, o Superior Tribunal de Justiça, rever as sentenças definitivas de outros tribunais, sob a alegativa de serem contrárias à Constituição (BONNET; MEDONÇA, 1997).

O controle de constitucionalidade de normas foi incorporado apenas pela Constituição de 1967, que conferia competência à Corte Suprema de Justiça para declarar a inconstitucionalidade ou inaplicabilidade de normas contrárias à Constituição. Estava sempre associado ao caso concreto e as decisões tinham efeitos inter partes. O procedimento poderia ser iniciado via ação direta ou por exceção em qualquer instância (BONNET; MEDONÇA, 1997).

A larga tradição em regimes autoritários, associada à completa falta de independência do Poder Judiciário, acabou por tornar irrelevante a atuação da justiça constitucional no país, que somente começa efetivamente a dar seus primeiros passos com a redemocratização, em 1992 (LÖSING, 2002). A Constituição deste ano, vigente atualmente, atribui ao Poder Judiciário a guarda da Constituição, cabendo, no entanto, à Corte Suprema, por meio de uma Câmara Constitucional, exercer a jurisdição constitucional de forma especializada e concentrada (LÖSING, 2002).

A Câmara Constitucional recebe a ação de inconstitucionalidade e a exceção de inconstitucionalidade. A ação de inconstitucionalidade pode se dar em relação a normas ou em relação a sentenças definitivas ou interlocutórias contrárias à Constituição. Já a exceção de inconstitucionalidade pode ser proposta por qualquer das partes, na contestação ou réplica, quando entenderem que a demanda ou a defesa se apoiem em norma inconstitucional. A exceção pode ocorrer também em segunda ou em terceira instância, na motivação do recurso ou em sua contestação (LÖSING, 2002).

Não há controle abstrato, a Câmara Constitucional deverá declarar a inaplicação da norma no caso concreto e a regra é do efeito inter partes das decisões, conforme o artigo 260 da Constituição. Segundo registro de Lösing (2002), no entanto, existe jurisprudência da Corte Suprema imputando efeito erga omnes às suas decisões nos casos em que ela própria revê, por meio de sessão Plenária, as decisões da Câmara Constitucional.

Dessa forma, as decisões de inconstitucionalidade proferidas pela Câmara Constitucional seguem tendo apenas efeitos inter partes, porém, se forem revisadas pelo Pleno da Corte Suprema, terão efeitos erga omnes.

Como assinala Alcalá (2003), a possibilidade de revisão das decisões da Câmara Constitucional retira a independência do órgão especializado para realizar o controle de constitucionalidade e confere ao Pleno da Corte Suprema o papel de verdadeiro guardião da Constituição.

A análise da estrutura da justiça constitucional no Paraguai demonstra outra inadequação dos critérios apontados por Tremps. O Paraguai, segundo o autor, enquadra-se no segundo sistema de justiça constitucional: o de órgão judicial especializado. Como foi ressaltado, entretanto, embora a Câmara Constitucional atue como órgão especializado, suas decisões podem ser revistas pelo Plenário da Corte Suprema, a quem cabe verdadeiramente o papel de guardião da Constituição. O Pleno da Corte, porém, não é órgão especializado, é o órgão de cúpula do Poder Judiciário.

Outra insuficiência no mesmo sistema é que ele não abrange as diferenciações que possam existir entre países que adotam o modelo de órgão especializado. A organização da jurisdição paraguaia é realizada, em princípio, por um órgão especializado que exerce o monopólio do controle de constitucionalidade. Muito 
embora a proteção dos direitos fundamentais possa ser realizada por qualquer juiz ou tribunal, por meio das garantias constitucionais, o controle de constitucionalidade somente pode ser feito pela Corte Suprema, de forma concentrada nos moldes já analisados.

Obviamente, todavia, esse não é o único padrão de justiça constitucional realizado por órgão judicial especializado. O sistema venezuelano mostrará que esse órgão pode, além de ser autônomo, executar a jurisdição constitucional compartilhada com outros órgãos.

\section{JUSTIÇA CONSTITUCIONAL NA VENEZUELA}

Na Venezuela, desde cedo, desenvolveu-se a tradição do controle de constitucionalidade concentrado, antecedendo, inclusive, as formulações europeias sobre o tribunal constitucional austríaco (BREWER-CARÍAS, 2011). Essa tradição remonta à Constituição de 1858, que, além de estabelecer a competência exclusiva da Corte Suprema de Justiça para se manifestar sobre a inconstitucionalidade das normas, ainda inovou com a criação de um instituto processual bem peculiar para o desenvolvimento da jurisdição constitucional na época: a ação popular direta de inconstitucionalidade (ALCALÁ, 2003).

Pela Constituição de 1961, entretanto, introduz-se o controle difuso que passa a conviver, desde então, com o controle concentrado exercido pela Suprema Corte de Justiça.

A Constituição vigente de 1999 mantém o modelo misto, mas inova com a criação da Câmara Constitucional do Tribunal Supremo, órgão especializado na jurisdição constitucional.

A Câmara Constitucional tem competência exclusiva para declarar a nulidade das leis, realizar controle de constitucionalidade preventivo dos tratados internacionais, revisar ofício da constitucionalidade dos decretos do Executivo, resolver as inconstitucionalidades por omissão do legislador nacional e revisar as sentenças que envolvam o exercício do controle de constitucionalidade difuso (BREWER-CARÍAS, 2011).

Embora a Câmara Constitucional seja um órgão especializado em jurisdição constitucional e suas decisões sejam vinculantes, inclusive, para as outras Câmaras do mesmo Tribunal - não podendo ser revistas nem mesmo pelo Pleno -, o controle de constitucionalidade, bem como a jurisdição de liberdades, é exercido por todos os juízes venezuelanos (BREWER-CARÍAS, 2011).

Nesse sentido, ao lado do Paraguai a Venezuela integraria o segundo sistema proposto por Tremps: o de jurisdição constitucional exercida por órgão judicial especializado.

Os dois exemplos apresentam, no entanto, situações bem peculiares que poderiam embasar a subdivisão do próprio sistema proposto pelo autor. Assim, poderia se falar em jurisdição constitucional exercida por órgão judicial especializado com monopólio do controle de constitucionalidade (Paraguai) e de jurisdição constitucional exercida por órgão judicial especializado com controle de constitucionalidade compartilhado com outros órgãos judiciais (Venezuela).

\section{JUSTIÇA CONSTITUCIONAL NA ARGENTINA}

A característica marcante da justiça constitucional na Argentina é a conservação, até os dias atuais, do modelo difuso de controle de constitucionalidade em sua formulação clássica.

Apesar de toda a influência que a região sofreu do modelo europeu, a Argentina resistiu ao controle concentrado, à ideia de Tribunal Constitucional, de controle abstrato e de eficácia erga omnes nas decisões em controle de constitucionalidade.

Na concepção de Dalla Via (2010), o contexto histórico que justificou a criação dos tribunais constitucionais europeus impede que o modelo seja transplantado para todos os países, especialmente para a Argentina, onde o modelo norte-americano foi adotado desde a independência, encontra-se arraigado na sua história constitucional e tem um funcionamento bastante razoável.

O controle de constitucionalidade não tem previsão expressa na Constituição. A própria jurisprudência da Corte Suprema foi delineando seus contornos. Em 1863 foi regulamentado o recurso extraordinário que possibilitava à Corte Suprema decidir definitivamente as questões relativas à inconstitucionalidade dos atos dos poderes públicos (DALLA VIA, 2010). 
A reforma constitucional em 1994 estabeleceu uma espécie de writ of certiorari, ao permitir certa discricionariedade da Corte Suprema para admitir o recurso extraordinário. As mesmas regras do modelo estadunidense passaram a ser aplicadas: a inconstitucionalidade é declarada no caso concreto e de forma incidental. A própria Corte Suprema já afirmou entendimento no sentido de excluir qualquer possibilidade de realizar controle abstrato, reafirmando a doutrina norte-americana de que não é função do Judiciário dar declarações gerais para fixar o alcance das normas (DALLA VIA, 2010).

Nesse sentido, ao longo dos anos a Suprema Corte sedimentou os seguintes critérios para a realização do controle de constitucionalidade: a) poderá ser suscitado por qualquer pessoa prejudicada por uma norma inconstitucional; b) só pode ser suscitado pelo prejudicado; c) não é cabível a impugnação de inconstitucionalidade se o objeto não for a inaplicabilidde da norma, e sim o estabelecimento de um regime normativo distinto, o que só caberia ao legislador; d) só há declaração de inconstitucionalidade se tiver sentença condenatória favorável ao impugnante; e) não há inconstitucionalidade se a questão for resolvida por princípios e regras diferentes da lei impugnada; e f) a impugnação deve ser formulada contra a parte que causou o prejuízo (DALLA VIA, 2010).

Embora as decisões de inconstitucionalidade da própria Suprema Corte não tenham efeitos erga omnes, sua jurisprudência, na lição de Dalla Via (2010, p. 42),

[...] cristalizan un plano de producción jurídica sobre el que nadie puede volver, salvo el propio tribunal si en un caso posterior análogo cambia su criterio, y aun así, la modificación no autoriza a sacudir retroactivamente la cosa juzgada de las decisiones adoptadas al abrigo de la jurisprudencia anterior.

Não há dúvida de que a justiça constitucional argentina enquadra-se na terceira sistematização de Tremps: jurisdição constitucional exercida por ógãos judiciais não especializados. Pode-se questionar, no entanto, se esse sistema é suficiente para abranger outras estruturas de justiça constitucional que o autor submete ao mesmo modelo, como o caso brasileiro, em que está presente, além do controle difuso, o controle concentrado e abstrato realizado pelo Supremo Tribunal Federal.

Novamente caberia uma subdivisão na proposta do tercerio sistema de Tremps: sistema de jurisdição constitucional realizada por órgãos judiciais não especializados sem monopólio de controle de constitucionalidade e sistema de jurisdição constitucional realizada por órgãos judiciais não especializados com monopólio de controle de constitucionalidade abstrato/principal.

\section{CONVERGÊNCIA DE MODELOS, HIBRIDIZACCÃO E MUDANÇAS NA CARACTERIZAÇÃO DE UM SISTEMA DE JURISDIÇÃO CONSTITUCIONAL}

A comparação das estruturas de justiça constitucional de apenas cinco países da América do Sul demonstra uma ampla diversidade de institutos e mecanismos processuais de defesa da Constituição. Nos cinco países analisados evidencia-se a criativa e peculiar combinação dos elementos de modelos clássicos contrapostos por Favoreu (2004), de tal forma que se torna impossível enquadrá-los em um único modelo denominado de "misto".

Por outro lado, a variedade dos sistemas é tamanha - os cinco países comparados apresentam diferenças marcantes na organização de sua justiça constitucional - que inviabiliza ou, pelo menos, torna insuficiente a tentativa de se criar "modelos" nos quais se possam enquadrar cada país.

Da mesma forma que a dicotomia entre os dois modelos não pode mais subsistir para analisar os diversos sistemas de jurisdição constitucional do mundo - como há algum tempo já vem defendendo a doutrina latino-americana (SEGADO, 2014) - a identificação de um modelo novo ou de novos modelos em contextos de profunda hibridização se torna uma tarefa quase impossível.

Na opinião de Segado (2014), atualmente, até entre os próprios modelos clássicos, pode-se identificar uma convergência entre seus elementos e não mais uma oposição tão evidente.

A própria Áustria, ainda em 1929, afastou-se do modelo kelseniano puro de controle concentrado abstrato, estabelecendo o instituto da reclamação inconstitucional, que permitia a parte no caso concreto, pela via incidental, e, após juízo prévio de inconstitucionalidade do órgão processante da demanda, suscitar o controle de constitucionalidade perante o Tribunal Constitucional. 
Nesse mesmo sentido, diversos outros tribunais europeus criaram mecanismos de controle incidental, seja pela via de remessa dos autos por juízes e tribunais ao Tribunal Constitucional, seja pela via de recurso constitucional (Alemanha) ou recurso de amparo (Espanha).

Também em relação aos efeitos das decisões que declaram a inconstitucionalidade de normas, percebe-se certa convergência: ainda que os efeitos inter partes sejam típicos do modelo norte-americano, a decisão acaba tornando-se vinculante pela regra da vinculação dos precedentes (stare decisis).

Embora não possa ser desenvolvido neste estudo o tema da convergência entre os modelos estadunidense e o europeu, essa breve ilustração reforça a ideia defendida ao longo do trabalho, de que a tentativa de se analisar a jurisdição constitucional (hoje universalizada em contextos democráticos) por meio de modelos dicotômicos, não é adequada.

Talvez a busca pela identificação de critérios pelos quais se possa caracterizar um sistema de justiça constitucional - tais como os propostos por Segado (controle da lei e controle da aplicação da lei/controle objetivo - controle subjetivo/competência para efetuar o controle de aplicação da lei e instância em que se inicia o controle, etc.) - seja teoricamente mais relevante e mais próxima da realidade sul-americana.

\section{CONCLUSÃO}

A estrutura e a organização da justiça constitucional no Chile, Peru, Paraguai, Venezuela e Argentina revelam a multiplicidade de elementos que compõem os sistemas jurisidicionais de proteção e defesa da Constituição na América do Sul.

Em meio a graves períodos de instabilidade política e turbulências econômicas e sociais, os países da região conseguiram, ao longo de sua história recente, construir sistemas próprios e criativos de jurisdição constitucional.

A proposta de Pablo Peréz Tremps para sistematizar alguns modelos de justiça constitucional na América Latina, mostrou-se inadequada para "enquadrar" alguns países, como o Peru, onde a jurisdição constitucional se dá tanto pelo Tribunal Constitucional quanto por órgãos judiciais especializados. Também não se revela adequada a caracterização da justiça constitucional do Chile como sistema de jurisdição realizada por Tribunal Constitucional com monopólio da jurisdição, pois o que há é o monopólio apenas do controle de constitucionalidade concentrado, mas não da jurisdição de liberdades.

Revela-se ainda insuficiente o sistema de órgão judicial especializado, pois, no caso do Paraguai, apesar de a Câmara Constitucional ser especializada e concentrar todas as demandas do controle incidental, o órgão que detém a última palavra em sede de controle de constitucionalidade é a Corte Suprema. Já na Venezuela, cuja Câmara Constitucional tem autonomia e exclusividade para realizar o controle concentrado de normas, a jurisdição constitucional é compartilhada com outros órgãos por meio do controle difuso.

O último sistema proposto pelo autor - o da jurisdição constitucional realizada por órgãos judiciais não especializados, também apresenta limitações, especialmente pelo fato de não abranger as profundas divergências entre os países agrupados, como a Argentina e o Brasil, por exemplo.

Tais constatações sugerem, por um lado, que é impossível se estabelecer um modelo único de justiça constitucional sul-americana e, por outro, que qualquer tentativa de se elaborar esquemas teóricos para enquadrar os países da região deverá enfrentar uma enorme dificuldade para agrupar sistemas tão diversificados.

\section{REFERÊNCIAS}

ALCALÁ, Humberto Nogueira. Los Tribunales Constitucionales de sudamérica a principios del siglo XXI. Ius et Praxis [on-line], 2003, v. 9, n. 2, p. 59-131. ISSN 0718-0012. Disponível em: http://dx.doi.org/10.4067/S0718-00122003000200003. Acesso em: 10 abr. 2018.

ALVARÉZ, Lautaro Ríos. El Nuevo Tribunal Constitucional Chileno. Anuario Iberoamericano de Justicia Constitucional, Madrid, n. 11, p. 243-268, 2007. ISSN 1138-4824. Disponível em: https://dialnet.unirioja.es/descarga/articulo/3764313.pdf. Acesso em: 18 jun. 2018.

BELAUNDE, Domingo Garcia. Los tribunales constitucionales en el America Latina. Revista de Derecho Político, n. 61, p. 309322, 2004. ISSN 0211-979X. Disponível em: http://www.corteidh.or.cr/tablas/12843a.pdf. Acesso em: 10 abr. 2018. 
BONNET, Juan Carlos Medonça; MEDONÇA, Daniel. La justicia constitucional en Paraguay. Anuario Iberoamericano de Justicia Constitucional, n. 1, p. 293-302, 1997. ISSN 1138-4824. Disponível em: https://dialnet.unirioja.es/descarga/articulo/1976352. pdf. Acesso em: 21 jun. 2018.

BREWER-CARÍAS, Allan. La acción popular de inconstitucionalidad en Venezuela y su ilegítima restricción por el juez constitucional. Estudios Constitucionales, a. 9, n. 2, p. 623-638, 2011. Versión on-line ISSN 0718-5200. Disponível em: http://www. scielo.cl/scielo.php?script=sci_arttext\&pid=S0718-52002011000200015\#7. Acesso em: 23 jun. 2018.

COUSO, Javier; HILBINK, Lisa. Del quietismo al activismo insipiente: las raíces institucionales e ideológicas de la defensa de los Derechos en Chile. In: HELMKE, Gretchen; FIGUEROA, Julio Rios (coord.). Tribunales Constitucionales en América Latina. 1. ed. Ciudad de México: Suprema Corte de Justicia de la Nación, 2010. Disponível em: http://www.uv.mx/veracruz/sea/files/2013/05/Tribunales-Constitucionales-en-America-Latina.pdf. Acesso em: 19 jun. 2018.

DALLA VIA, Alberto Ricardo. La justicia constitucional en Argentina. Anuario Iberoamericano de Justicia Constitucional, n. 1, p. 35-48, 1997. ISSN 1138-4824. Disponível em: https://dialnet.unirioja.es/descarga/articulo/1976242.pdf. Acesso em: 18 jun. 2018.

DALLA VIA, Alberto Ricardo. Modelos, Tribunales y Sentencias Constitucionales. In: BOGDANDY, Armin von Morales; ANTONIAZZI, Mariela; FERRER MAC-GREGOR, Eduardo (coord.). La justicia constitucional y su internacionalización. ¿Hacia un lus constitutionale commune en América Latina? Tomo I. México: Universidad Autónoma de México; Instituto de Investigaciones Jurídicas; Ciudad Universitaria, 2010. Disponível em: http://bibliohistorico.juridicas.unam.mx/libros/6/2894/18.pdf. Acesso em: 18 jun. 2018.

FAVOREU, Louis. As cortes constitucionais. São Paulo: Lande Editora, 2004.

FIX-ZAMUDIO, Héctor. La justicia constitucional en América Latina. In: El constitucionalismo en las postrimerías del siglo XX. Tomo IV. México: Instituto de Investigaciones Jurídicas de la Universidad Nacional Autónoma del México, 1989. Disponível em: http://ru.juridicas.unam.mx/xmlui/handle/123456789/57087. Acesso em: 18 jun. 2018.

LÖSING, Norbert. La Justicia constitucional en Paraguay y Uruguay. Anuario de Derecho Constitucional Latinoamericano, n. 1, p. 109-133, 2002. ISSN 1510-4974. Disponível em: http://www.juridicas.unam.mx/publica/librev/rev/dconstla/cont/2002/pr/ pr8.pdf. Acesso em: 18 jun. 2018.

SARAIVA, Francisco Morales El circuito de la jurisdicción constitucional en el Perú (relaciones complementarias entre el Tribunal Constitucional y el Poder Judicial). In: CRUZ, Eto Gerard (coord.). Treinta años de jurisdicción constitucional en el Perú. Tomo II. Lima: Centro de Estudios Constitucionales, 2014. Disponível em: https://www.tc.gob.pe/wp-content/uploads/2018/10/libro_30_anos_tomo2.pdf. Acesso: 23 abr. 2019.

SEGADO, Francisco Fernández. La búsqueda de una nueva tipología explicativa de los sistemas de justicia constitucional. In: CRUZ, Eto Gerard (coord.). Treinta años de jurisdicción constitucional en el Perú. Tomo II. Lima: Centro de Estudios Constitucionales, 2014. Disponível em: https://www.tc.gob.pe/wp-content/uploads/2018/10/libro_30_anos_tomo2.pdf. Acesso: 23 abr. 2019.

SUÁREZ, Omar Sar. La jurisdicción constitucional en el Perú. In: CRUZ, Eto Gerard (coord.). Treinta años de jurisdicción constitucional en el Perú. Tomo II. Lima: Centro de Estudios Constitucionales, 2014. Disponível em: https://www.tc.gob.pe/wp-content/uploads/2018/10/libro_30_anos_tomo2.pdf. Acesso em: 23 abr. 2019.

TREMPS, Pablo Perez. La justicia constitucional en la actualidad. Especial referencia a América Latina. Revista Brasileira de Direito Constitucional, n. 1, p. 33-34, jan./jun. 2003. ISSN 1678-9547. Disponível em: http://www.esdc.com.br/seer/index.php/ rbdc/article/view/21. Acesso em: 10 abr. 2018.

VILLALOBOS, Marco F. Feoli. De la justicia constitucional o las justicias constitucionales: la contribución de América Latina (los casos de Colombia y Costa Rica). ENCUENTRO DE LATINOAMERICANISTAS ESPAÑOLES: CONGRESO INTERNACIONAL, 14., Santiago de Compostela, Espanha: Universidade de Santiago de Compostela; Centro Interdisciplinario de Estudios Americanistas Gumersindo Busto; Consejo Español de Estudios Iberoamericanos, sept. 2010. p. 2.094-2.112. Disponível em: https://halshs. archives-ouvertes.fr/halshs-00531530. Acesso em: 15 jun. 2018. 